\title{
Insulin-like growth factor II prevents apoptosis in a human teratoma derived cell line
}

\author{
Department \\ of Pathology, \\ Faculty of Veterinary \\ Medicine, Swedish \\ University of \\ Agricultural Sciences, \\ PO Box 7028 , \\ S-75007 Uppsala, \\ Sweden \\ M Granerus \\ P Bierke \\ W Engström \\ Laboratory \\ of Stem Cell Biology, \\ Department of \\ Anatomy, University \\ of Cambridge, \\ Downing Street, \\ Cambridge, UK \\ W Zumkeller \\ J Smith \\ P Schofield \\ Correspondence to: \\ Dr W Engström. \\ Accepted for publication \\ 21 February 1995
}

cells. Unlike necrosis, this process is not accompanied by inflammation and its prevalence is often underestimated because of the relatively small effect it has on local tissue integrity. ${ }^{2}$

Apoptosis occurs normally during embryonic development, particularly in complex organs where there is much cell turnover and selection during ontogeny. For example many neurones die in the CNS, having failed to reach their target cell type, and self reactive $T$ cells are eliminated within the thymus. Where tissue remodelling is prevalent, programmed cell death is again an important factor in the generation of form, for example in the limb.

Apoptosis is also seen widely in tumours, often paradoxically in rapidly growing tumours, indicating massive cell turnover, but in some situations it is clear that mutations in genes controlling entry into apoptosis have been selected for. The Bcl 2 gene product is thought to act both in development and when abnormally expressed in a tumour. Increased expression of the gene in transgenic mice substantially increases their risk of neoplasia, indicating that in some circumstances tipping the balance in favour of survival rather than cell death results in promotion of other genomic changes leading to frank neoplasia. The effects of $\mathrm{Bcl}-2$ are at least in part abrogated by the $\mathrm{Bax}-1$ gene product, and the balance between these two is clearly important in deciding whether a cell undergoes another round of division or enters a terminal apoptotic pathway.

Determination as to which of these routes will be taken appears to be largely under the control of the p53 gene product, which is now thought to monitor the amount of chromosomal damage in cells. ${ }^{3}$ Generation of $\mathrm{p} 53$ deficient mice results in massive suppression of apoptosis in response to DNA damaging reagents, which leads to an increase in the tumourigenic potential of such insults. Taken together, these data suggest that apoptosis may play a role in the suppression of tumour formation by targeting aberrant cells for sudden death, preventing expansion of their progeny.

One way in which apoptosis may be prevented is by the provision of serum or other growth factors, as has been shown to date for muscle cells, embryonic kidney cells, lymphocytes, fibroblasts, neuronal cells, and astrocytes. ${ }^{4}$ The presence of factors permitting survival seems either to abrogate other signals including cell suicide or perhaps to prevent the occurrence of the default option on factor withdrawal. Recent data have indicated that c-myc expression is not only linked to continued cell proliferation but in the right context will induce cell death. In many tumours myc and 
Bcl-2 mutations are found together, suggesting that the enhanced expression of c-myc needed for proliferation is made safe by the upregulation of Bcl-2. Such oncogene cooperation may be much more widespread than was formerly believed.

We have previously shown that Tera-2, a clonal cell line derived from a human teratocarcinoma, expresses high levels of c-myc in both proliferative and quiescent phases of its growth, and shows a dependence for its survival on the addition of exogenous insulin-like growth factors. We show here that Tera-2 enters an apoptotic pathway on serum withdrawal, which can be rescued by the addition of insulinlike growth factor II (IGF-II). Tera-2 only makes small quantities of IGF-II, and is unable to complete an autocrine loop in culture; however, in primary tumours we demonstrate the synthesis of significant levels of IGF-II in three out of five testicular neoplasms, indicating that this factor may act as a survival factor during human teratocarcinogenesis.

\section{Methods}

CELL CULTURE

The human teratoma cell line Tera- 2 clone 13 was routinely passaged in $\alpha$ modified Eagle's medium ( $\alpha$-MEM) supplemented with $10 \%$ heat inactivated fetal calf serum as described in Biddle et al. ${ }^{5}$ Cells used for experimental purposes were seeded onto gelatin coated glass coverslips in $30 \mathrm{~mm}$ plastic Petri dishes at a concentration of $10^{5}$ cells per dish. Cells were allowed to attach and were thereafter maintained in $10 \%$ serum for 72 hours before each experiment. For serum-free experiments the cells were washed twice in phosphate buffered saline (PBS) and in serum-free $\alpha$-MEM. The medium was then replaced with alpha/Ham (a 50/50 mixture of $\alpha-M E M / H a m$ 's F12 medium, supplemented with $10 \mu \mathrm{g} / \mathrm{ml}$ iron loaded transferrin as described ${ }^{5}$ ). Recombinant insulin-like growth factors were obtained from $\mathrm{R}$ and $\mathrm{D}$ Systems through British Biotechnology (Oxford) and reconstituted according to the manufacturers' instructions. The vehicle used contained a final concentration of $50 \mu \mathrm{g} / \mathrm{ml}$ bovine serum albumin (BSA; Sigma RIA grade). For determination of nucleosome ladders, cells were maintained in $75 \mathrm{~cm}^{2}$ tissue culture flasks (Nunc, GIBCO) and used when subconfluent.

DETERMINATION OF NUCLEAR MORPHOLOGY Glass coverslips with cells attached were rinsed in PBS, and instantly stained with $1 \%$ acridine orange as described by Bolund. ${ }^{6}$ The glass coverslips were illuminated at $435 \mathrm{~nm}$ and photographed in a Leitz fluorescence microscope.

DETERMINATION OF CHROMATIN DEGRADATION Two $75 \mathrm{~cm}^{2}$ tissue culture flasks of cells per experimental group were incubated with $0.25 \%$ trypsin at room temperature until cells just detached. The trypsin activity was stopped by adding $1 \% \mathrm{vol} / \mathrm{vol}$ final concentration soybean trypsin inhibitor. The cell suspension was collected by low speed centrifugation and high molecular weight DNA isolated according to Pesce et al. ${ }^{7}$ The DNA extract was normalised to cell number and $\mu \mathrm{g}$ aliquots were electrophoresed on a $0.8 \%$ agarose gel in Tris/ acetate/EDTA. Gels were subsequently stained with ethidium bromide and visualised by ultraviolet illumination.

NUCLEIC ACID MANIPULATIONS

RNA was extracted according to Schofield and Tate $^{8}$ and polyadenylated RNA was purified using oligo dT cellulose (Pharmacia type 7 ). The cDNA probe for c-myc was the kind gift of Dr Natalie Teich, ICRF, London, and the GAPDH the gift of Dr Peter Curtis, Wistar Institute, Philadelphia. Probes were labelled with ${ }^{32} \mathrm{P}$ dATP by random hexanucleotide priming as described by Feinberg and Vogelstein. ${ }^{9}$ Northern blotting was carried out according to Hyldahl et $a l^{10}$ and filters washed to a final stringency of $0 \cdot 1 \times \mathrm{SSC}(\mathrm{NaCl} /$ sodium citrate $)$ at $55^{\circ} \mathrm{C}$.

\section{EXTRACTION OF IGF-II}

Testicular tissues were obtained from patients after orchidectomy. Normal control testis, testicular tumour tissue, and adjacent tumourfree testicular tissue samples were minced in $1 \mathrm{M}$ acetic acid in ethanol (1:4 weight of tissue/ volume), sonicated for 10 seconds, then spun at $2000 \times g$ for 10 minutes. The supernatant was removed and frozen at $-20^{\circ} \mathrm{C}$ until further use.

INSULIN-LIKE GROWTH FACTOR DETERMINATION Acid ethanol extracts of testicular tissue were equilibrated in $1 \mathrm{M}$ acetic acid to separate immunoreactive IGF from their binding proteins, and chromatographed on a Sephacryl S-100 HR column (Pharmacia) at a flow rate of $4.5 \mathrm{ml} /$ hour. Fractions equivalent to a $\mathrm{kd}$ of $0 \cdot 5-0 \cdot 87$ were analysed by IGF-I or IGF-II radioimmunoassay. IGF-I was measured using truncated IGF-I as a ligand and polyclonal antibodies raised in rabbits against human IGFI (from Prof P Gluckman, Auckland, New Zealand). IGF-II was measured in an assay using recombinant IGF-II, the gift of Kabi Pharmacia, Stockholm, and hen yolk antibodies, as described in Schofield et al. ${ }^{11}$

\section{Results}

EFFECTS OF IGF-II ON APOPTOSIS IN HUMAN TERATOMA CELLS

The appearance of nuclear fragmentation, characteristic of apoptotic changes, was sought for over increasingly long periods of serum deprivation. After 12 hours, approximately one fifth of the cells had undergone apoptotic changes as judged by nuclear morphology (fig 1); this proportion increased with time. In contrast, cultures maintained in $10 \%$ fetal calf serum after equivalent washing contained less than $10 \%$ apoptotic cells. Figure 2 shows that 


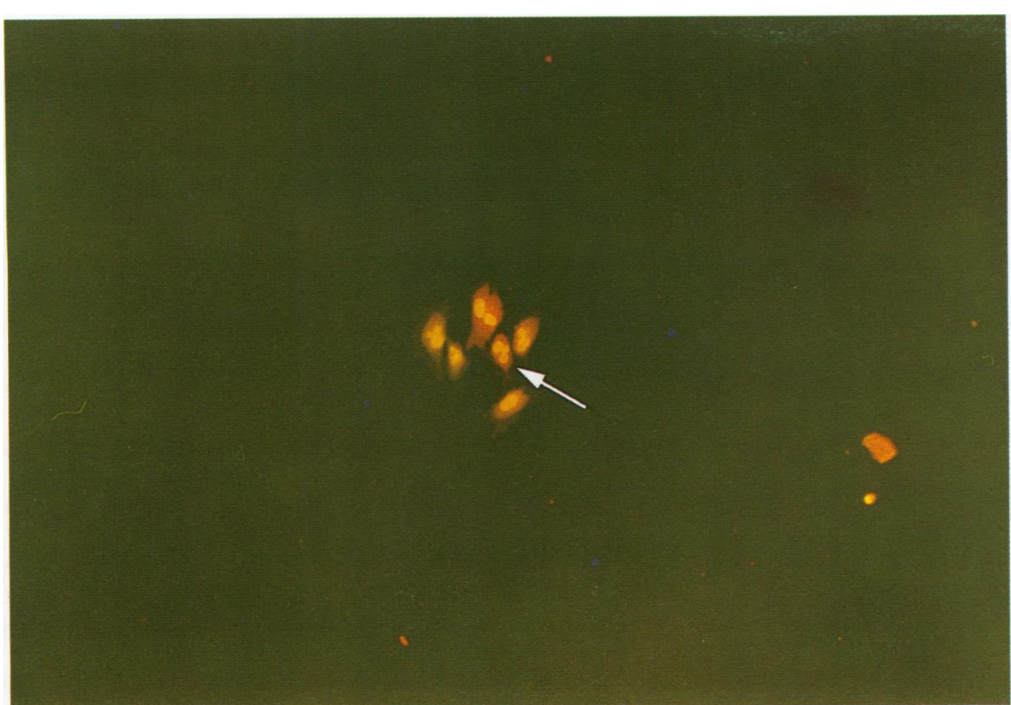

Figure 1 Morphological appearance of a Tera 2 cell colony 24 hours after serum withdrawal. Acridine orange was used to visualise fragmented nuclei (arrow).

the population could be protected from apoptosis by the addition of $1-100 \mathrm{ng} / \mathrm{ml}$ IGF-II. The proportion of apoptotic cells fell from $70 \%$ to $40 \%$ when assayed over a 24 hour period. This effect was saturated by $10 \mathrm{ng} / \mathrm{ml}$ IGF-II, indicating that IGF-II was not the only factor required to completely prevent cell death. Figure 3 shows the proportion of cells at different times after serum deprivation. The number of dying cells increases slightly with time and this effect is ameliorated by the addition of $10 \mathrm{ng} /$ $\mathrm{ml}$ IGF-II throughout the period. To confirm that the nuclei seen were apoptotic, high molecular weight DNA was prepared from cultures starved of serum or supplemented with $10 \mathrm{ng} /$ ml IGF-II. Whereas DNA from cells growing in serum appeared mainly as a high molecular weight band, cells exposed to serum-free medium showed a characteristic nucleosomal ladder (fig 4). This ladder was less pronounced in cells exposed to serum-free medium supplemented with IGF-II. These results confirm the conclusion drawn from the acridine orange

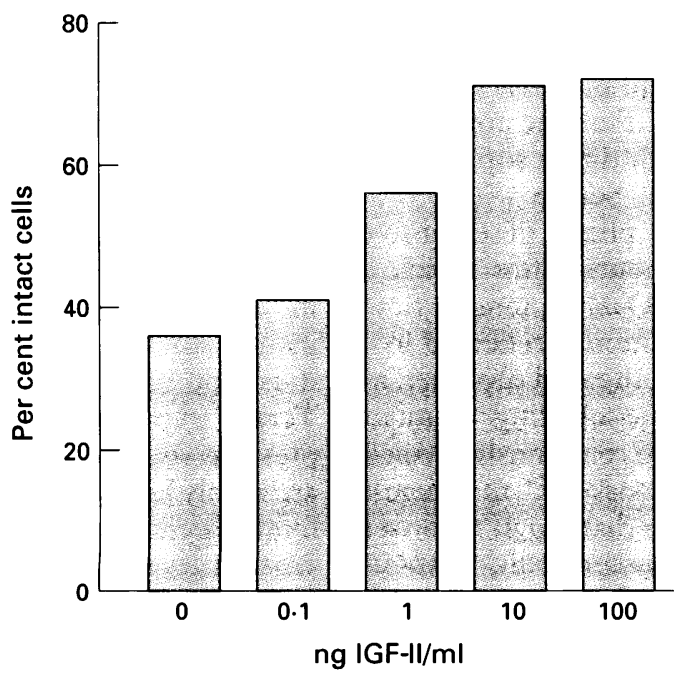

Figure 2 The proportion of intact cell nuclei after 24 hours exposure to different concentrations of IGF-II. The cells were stained with acridine orange and the proportion of intact nuclei counted in a fluorescence microscope at $435 \mathrm{~nm}$. Each experimental point is based on counting at least 200 cells.

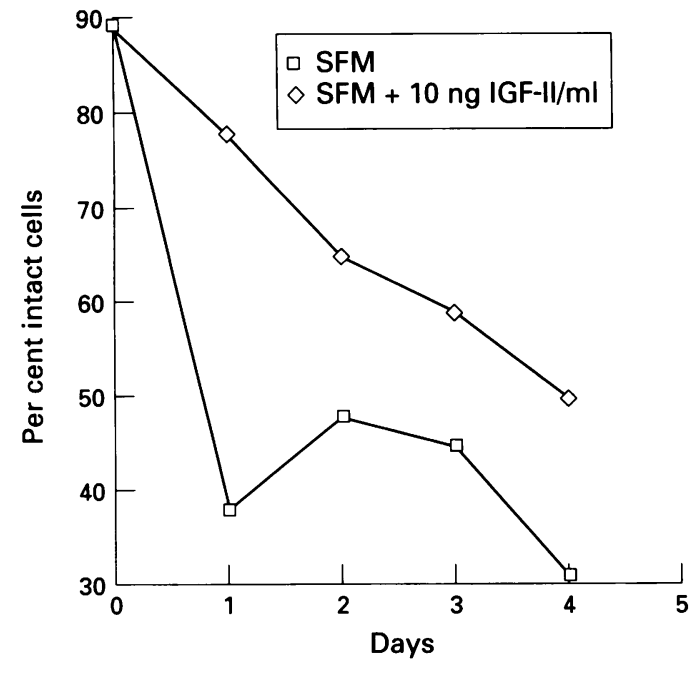

Figure 3 The proportion of intact nuclei after 24-72 hours exposure to serum-free medium without supplements, or supplemented with $10 \mathrm{ng} I G F-I I / \mathrm{ml}$. The cells were stained with acridine orange and the proportion of intact nuclei counted in a fluorescence microscope at $435 \mathrm{~nm}$. Each experimental point is based on counting at least 200 cells.

staining of cells and show that serum starvation generates a form of cell death characteristic of apoptosis.

C-myc AND SERUM DEPRIVATION

It has previously been reported that high levels of expression of c-myc predisposes cells to programmed cell death in the absence of permissive factors such as serum, or perhaps other defined growth factors. ${ }^{1213}$ We have previously reported that Tera-2 shows massive levels of c-myc expression, ${ }^{11}$ both in its proliferative and differentiated states, and it seemed pertinent to ask if levels of c-myc expression remained elevated under conditions of serum deprivation. Figure 5 shows the expression of the c- $m y c$ proto-oncogene in Tera- 2 cells exposed to $10 \%$ serum, serum-free medium, or serumfree medium containing $10 \mathrm{ng} / \mathrm{ml}$ IGF-II. It can be seen that the intensity of the major transcript is unchanged, irrespective of the composition of the medium, indicating that in these cells $m y c$ is unresponsive to exogenous growth factor provision.

IGF-I AND IGF-II IN PRIMARY TUMOURS

The concentrations of immunoreactive IGFI and IGF-II in normal testis and testicular tumours are shown in the table. In three out of five testicular tumours tissue specimens were also obtained from histologically normal surrounding tissue. The mean concentration of IGF-I in normal testicular extracts was $47 \mathrm{ng} / \mathrm{g}$. Apart from one seminoma (224 ng/g), all tumour samples had IGF-I levels within the range of normal testis. The mean level of IGFII in testis extracts was $109 \mathrm{ng} / \mathrm{g}$, in comparison to an average for tumours of $528 \mathrm{ng} / \mathrm{g}$. In the two seminomas the IGF-II content was nearly 10-fold higher than in adjacent tumour-free tissue from the same patients. In addition the level in one teratoma was higher than in normal testicular tissue from the same patient. 


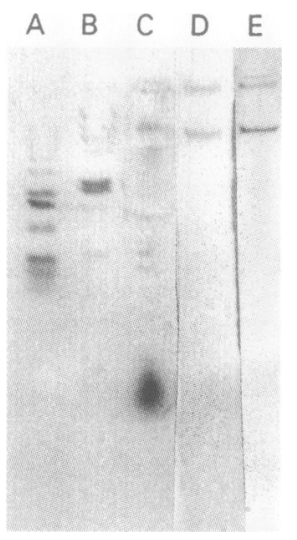

Figure 4 Qualitative appearance of high molecular weight DNA extracted from Tera 2 cells after 24 hours exposure to serum-free medium $(C)$, $10 \%$ serum (D) or serumfree medium supplemented with $10 \mathrm{ng} I \mathrm{IF} F-I I / \mathrm{ml}(E)$. (A) $=B R L 1 \mathrm{~kb} D N A$ ladder and $(B)=a$ Hind III digest of lambda DNA; These were used as controls. The DNA samples were electrophoresed on an agarose gel containing ethidium bromide and visualised on an ultraviolet transilluminator, converted to a negative-positive image by the use of Mitsubishi video camera equipment.
Immunoreactive IGF-I and IGF-II concentrations in acid ethanol extracts of testis and testicular tumours ( $\mathrm{ng} / \mathrm{g}$ tissue) after gel chromatography at low $p H$. Values of supposed normal testis of tumour patients are indicated $(t)$ below the tumour extract values of the respective patient tissue (*)

\begin{tabular}{l}
\hline Tissue extracts \\
\hline Normal testis
\end{tabular}

\begin{tabular}{lccc} 
Mean (SD) & & $47(6)$ & $109(101)$ \\
Seminoma & $* 1$ & 34 & 826 \\
& +2 & 32 & 368 \\
Seminoma & $* 2$ & 224 & 1376 \\
& $\dagger 2$ & 21 & 131 \\
Seminoma & $* 3$ & 54 & 44 \\
Teratoma & $* 4$ & 40 & 328 \\
& $\dagger 4$ & 34 & 160 \\
Teratoma & $* 5$ & 35 & 64 \\
Mean (median) & & $77(40)$ & $528(328)$ \\
\hline
\end{tabular}

\section{Discussion}

In this study we have shown that a human teratoma derived cell line, Tera-2, responds to serum withdrawal by morphological changes typical of apoptosis. Like other apoptotic cells, dying Tera-2 cells shrink and lose contact with their neighbours. Prominent nuclear changes consistent with apoptosis also seen in other cell types were also observed in Tera-2; the effect was soon induced and fragmented nuclei were observed 12 hours after serum withdrawal. This effect could be at least partially reversed by the addition of physiological doses of insulin-like growth factors. These findings are in agreement with our previous report ${ }^{5}$ in which we showed that Tera-2 was dependent on IGF-I or IGFII for its survival in serum-free medium, and that the effect of these peptides is to promote the survival of the cell population rather than promote entry into $S$ phase. This study thus extends the earlier work and provides evidence that the survival effect of IGF on the population noted previously is through direct suppression of programmed cell death. Serum withdrawal leads very swiftly into a phase of extensive apoptosis, within 24-48 hours, after which a steady state is reached. Over a longer time scale, this steady state position is reflected in a static population of cells with rapid turnover, as shown by in vivo thymidine labelling. ${ }^{5}$ Similar states have been reported previously, which have led Wyllie and co-workers ${ }^{14}$ to suggest the existence of an intermediate high turnover population state in which susceptibility to apoptosis is high despite the fact that cells are competent to enter the proliferation cycle. Quantitative as well as qualitative considerations may therefore be important in deciding whether the population then ultimately increases or decreases in size. Such population dynamics may in principle result in very rapid regulation of cell numbers when conditions change to favour expansion or contraction. Similar models have been proposed on cybernetic grounds for the rapid induction of enzyme activities in metabolic pathways subject to substrate cycling. ${ }^{15}$ The rate limiting factors for a tumour cell population may be either nutritional, or as we see here, specific growth regulatory peptides. Apoptosis has frequently been observed in neoplastic tissues, although it is clearly not the sole mode of cell death. It has been claimed that apoptosis is the most significant component of the continuous loss of cells that characterise most tumours; however, substantiating quantitative data are still scanty. ${ }^{216}$ Both irradiation and chemotherapy have been shown to induce apoptosis in tumour cells, but at high doses they will also include death by other means. ${ }^{1718}$

It has been suggested that expression of c-myc plays a role in the susceptibility of cells to apoptosis. Evan et $a l^{19}$ showed that fibroblasts subjected to forced c-myc expression in the absence of serum rapidly entered an apoptotic pathway in preference to entering quiescence. This effect can also be induced by leucine depletion, thymidine block, or application of topoisomerase inhibitors. Other proto-oncogenes also appear to rescue cells from a high turnover state into a population expansion phase. Among these is the $\mathrm{Bcl}-2$ gene, originally isolated as a transforming sequence from $B$ cell lymphomas. Presence of an activated Bcl-2 gene in a $m y c$ overexpressing cell seems to be permissive for continued proliferation in the absence of exogenous factors which would normally be required to prevent apoptosis. Interestingly the coincidence of $m y c$ and Bcl-2 mutations in tumours is very high, perhaps indicating that this is an advantageous combination of mutations for a tumour cell to carry. If autocrine or paracrine IGF expression is also permissive for proliferation in the presence of activated $m y c$ genes this may explain the predominance of tumours which either make or show dependence on IGF-I or IGF-II. Such an increase in IGF-II levels is seen in three out of five testicular tumours examined, the highest levels of expression being found in a seminoma. In a previous study ${ }^{20}$ two out of three seminomas were shown to express IGF-II transcripts, with pure embryonal carcinoma being the richest source of IGF-II RNA; a teratoma was shown to be negative for IGF-II transcripts.

While Tera-2 makes a small amount of high molecular weight IGF-II itself, this is clearly insufficient to drive autocrine growth; however, it is not quantitatively clear how accurately Tera-2 represents the pattern of gene expression seen in these tumours, many of which are highly heterogeneous. Both seminomas and teratocarcinomas are shown to express increased levels of IGF-II peptide here, but not IGF-I. The testis is normally a moderately rich source of IGF-I, being elaborated by the Sertoli cells, ${ }^{21}$ and possibly by Leydig cells, although this is only reported in the rat. ${ }^{22}$ The sole report of IGF-II is in human testicular connective tissue, ${ }^{23}$ but in this report, the authors failed to detect IGF-I transcripts at all, which is in conflict with previous reports. 
It is interesting that an increase in IGF-I expression is not apparently selected for in the tumours examined. Although it cannot be excluded that the IGF-I detected in this study is from contaminating blood, the concentrations of IGF-II reached are very high, which, together with the previous study demonstrating RNA transcripts, indicates that this IGF-II is most likely to be of tumour origin.

We have previously determined that Tera-2 continues to make c-myctranscripts and protein (Evan G, Schofield PN, unpublished data) when made to differentiate with retinoic acid. ${ }^{24}$ Such differentiated cells remain viable and quiescent for many weeks with no detectable DNA synthesis or turnover. This is in contrast to the situation seen where induction of quiescence by serum deprivation results in cell death. This comparison indicates that other molecular mechanisms must be operating in differentiated cells to suppress the tendency of $m y c$ expressing cells to enter an apoptotic pathway. Interestingly, a study carried out on primary testicular tumours showed that seminoma and malignant teratoma with differentiated elements expressed high levels of $c-m y c$, and that these were associated on average with a better prognosis. We suggest that expression of high levels of c-myc, while forcing cells into the cell cycle, carries with it a quantitative dependence on either growth factor provision or mutation of genes such as Bcl-2. In the absence of such factors, the enhanced tendency to apoptosis might predispose to the ultimate demise of the tumours; particularly in the face of irradiation or chemotherapeutic challenge. This model would predict that in testicular tumours expressing high levels of $c-m y c$, poor prognosis would only be associated with those coexpressing high levels of IGF-I or IGF-II. Quantitative considerations may be very important with regard to the effect of growth factor expression. Loss of the genomic imprint of IGF-II seems to be a common feature of all classes of testicular tumour, ${ }^{25}$ and probably occurs before the allelic loss on chromosome 11 reviewed elsewhere. ${ }^{26}$ Loss of an imprint would be expected to increase levels of IGF-II expression. There are insufficient data included in this study to test this hypothesis, but it is clear that further work will clarify the potential collaboration between IGF-II, acting as a tumour cell survival factor, and c-myc.

This study was supported by grants from Cancerfonden, Barncancerfonden, Magnus Bergvalls stiftelse, and the Cancer Research Campaign of Great Britain. WE was the recipient of an UICC ICRETT award. Professor Christopher F Graham FRS is gratefully acknowledged for generous advice and fruitful comments on the manuscript.

1 Raff MC. Social controls on cell survival and cell death. Nature 1992;356:397-400.

Nature 1992;356:397-400.
2 Wyllie AH. Apoptosis. Br f Cancer 1993;67:205-8.

3 Prives C, Manfredi JJ. The p53 tumor suppressor protein. Prives C, Manfredi JJ. The p
Genes Dev 1993;7:529-34.

4 Smith J, Fowler G, Schofield PN. Programmed cell death is inhibited by IGFII. Cell Death Differ (in press).

5 Biddle C, Li C, Schofield PN, Tate VE, Hopkins B, Engström W, Huskisson N \& Graham CF. Insulin like growth factors and the multiplication of Tera $2-a$ human teratoma derived cell line. $\mathcal{F}$ Cell Sci 1988;90:475-485.

6 Granerus M, Bierke P, Engström W. The effects of leukemia inhibitory factor (LIF) on cell multiplication and locomotion in human teratocarcinoma cells. Int $\mathcal{f}$ Oncol 1994; 516:1419-23.

7 Pesce M, Farrace M, Piacentini M, Dolci S, de Felici M. Stem cell factor and leukemia inhibitory factor promote primordial germ cell survival by suppressing programmed cell death. Development 1993;118:1089-94.

8 Schofield PN, Tate VE Regulation of human insulin like growth factor II transcription in fetal and adult tissues. Development 1987;100:693-703.

9 Feinberg AP, Vogelstein B. A technique for radiolabelling DNA restriction endonuclease fragments to high specific activity. Anal Biochem 1983;132:6-13.

10 Hyldahl L, Engström W, Schofield PN. Stimulatory effects of basic fibroblast growth factor on the human embryonic of basic fibroblast growth factor on the

11 Schofield PN, Granerus M, Tally M, Engström W. The biological effects of high molecular form of IGF-II in a human pluripotential teratocarcinoma cell line. Anticancer Res 1987;14:533-8.

12 Granerus M, Bierke P, Engström W. The effects of leukemia inhibitory factor on cell proliferation migration and apoptosis in a human teratocarcinoma cell line in vitro. Int $\mathcal{f}$ Oncol 1994;5:1419-23.

13 Harrington EA, Bennett MR, Fanidi A, Evan GI. C-myc induced apoptosis in fibroblasts is inhibited by specific cytokines. EMBO $f$ 1994;13:3286-95.

14 Dive C, Wyllie AH. Apoptosis and cancer chemotherapy. In: Hickman JA, Tritton TT, eds. Frontiers in pharmacology - cancer chemotherapy. Oxford: Blackwell, 1992.

15 Newsholme EA. Rapid induction of enzyme activity. Nutrition 1993;9:271-3.

16 Moore JV. Death of cells and necrosis of tumours. In: Potten CS, ed. Perspectives in mammalial cell death. Oxford: Oxford University Press, 1987:295-325.

17 Eastman A. Activation of programmed cell death by anti cancer agents. Cisplatinum as a model system. Cancer cells 1991;2:275-80.

18 Lennon SV, Martin SI, Cotter TG. Induction of apoptosis in tumour cell lines by widely diverging stmuli (Abstract) Biochem Soc Trans 1990;18:343.

19 Evan GI, Wyllie AH, Gilbert CS, Littlewood TD, Land H, Brooks $\mathrm{M}$, et al. Induction of apoptosis in fibroblasts by c-myc protein. Cell 1992;69:119-29.

20 Engström W, Hopkins B, Schofield PN. Expression of growth regulatory genes in human testicular tumours. Int f Androl 1987;10:79-84.

21 Forti G, Vanelli GB, Barni T, Balboni GC, Orlando C, Serio $M$. Sertoli germ cells interactions in the human testis. F Steroid Biochem Mol Biol 1991;43:419-22.

22 Lin M, Jones RC, Blackshaw AW. The cycle of the seminiferous epithelium in the Japanese quail and estimation of its duration. $\mathcal{F}$ Reprod Fertil 1990;88:481-90.

23 Zhou B, Watts LM, Huston JM. Germ cell development in neonatal mouse testis in vitro requires Müllerian inhibitory substance. F Urol 1993;150:613-6.

24 Schofield PN, Engström W, Lee A, Biddle C, Graham CF. Expression of c-myc during differentiation of a human teratocarcinoma cell line-Tera 2. $\mathcal{f}$ Cell Sci 1987;88: $57-64$.

25 Ward A, Bierke P, Pettersson E, Engström W. Insulin like growth factors. Growth, transgenes and imprinting. Zool Sci 1994;11:167-74.

26 Schofield PN, Engström W. Insulin like growth factors in human cancer. In: PN Schofield, ed. Insulin like growth factors. Oxford: Oxford University Press, 1992:130-47. 